\title{
Atmospheric Circulation Response to an Instantaneous Doubling of Carbon Dioxide. Part II: Atmospheric Transient Adjustment and Its Dynamics
}

\author{
YUTIAN WU \\ Courant Institute of Mathematical Sciences, New York University, New York, New York \\ Richard Seager, Tiffany A. Shaw, Mingfang Ting, and NaOmi Naik \\ Lamont-Doherty Earth Observatory, Columbia University, Palisades, New York
}

(Manuscript received 24 February 2012, in final form 27 July 2012)

\begin{abstract}
The dynamical mechanisms underlying the transient circulation adjustment in the extratropical atmosphere after the instantaneous doubling of carbon dioxide are investigated using the National Center for Atmospheric Research Community Atmosphere Model version 3 coupled to a Slab Ocean Model. It is shown that the transient process during the first few months of integration is important in setting up the extratropical circulation response in equilibrium such as the poleward shift of the tropospheric jet streams. Three phases are found during the transient thermal/dynamical adjustment in the Northern Hemisphere: 1) a radiatively driven easterly anomaly in the subpolar stratosphere, 2) an acceleration of the westerly anomaly in the subpolar stratosphere as a result of anomalous planetary-scale eddy momentum flux convergence, and 3) a "downward migration" of the westerly anomaly from the lower stratosphere to the troposphere, followed by the tropospheric jet shift. Several proposed mechanisms for inducing the poleward shift of the tropospheric jet streams are examined. No significant increase in eddy phase speed is found. The rise in tropopause height appears to lead the tropospheric jet shift but no close relation is observed. The length scale of transient eddies does increase but does not lead the tropospheric jet shift. Finally, the tropospheric jet shift can be captured by changes in the index of refraction and the resulting anomalous eddy propagation in the troposphere.
\end{abstract}

\section{Introduction}

Comprehensive climate models for the Coupled Model Intercomparison Project phase 3 (CMIP3) and Intergovernmental Panel on Climate Change the Fourth Assessment Report (IPCC AR4) have projected many changes in the general circulation of the atmosphere in response to increased carbon dioxide $\left(\mathrm{CO}_{2}\right)$ concentration. For example, Yin (2005) found a consistent poleward and upward shift of the midlatitude storm tracks along with poleward shifts of the surface wind stress and midlatitude precipitation zones. The changes in the location and intensity of the storm tracks are also closely related to the poleward displacement of the tropospheric zonal jets (Kushner et al. 2001) and the poleward expansion of the Hadley cell (Lu et al. 2007); however,

Corresponding author address: Yutian Wu, Courant Institute of Mathematical Sciences, New York University, New York, NY 10012.

E-mail: yutian@cims.nyu.edu what causes these circulation changes is not entirely clear.

In this study the transient atmospheric circulation response to increased greenhouse gases (GHGs) is investigated using the National Center for Atmospheric Research (NCAR) Community Atmosphere Model version 3 (CAM3) coupled to a Slab Ocean Model (SOM) when the $\mathrm{CO}_{2}$ concentration in the atmosphere is instantaneously and uniformly doubled. While the CMIP3/ IPCC AR4 climate models more realistically gradually increase the $\mathrm{CO}_{2}$ concentration, these simulations are always in quasi-equilibrium and thus do not provide evidence on how and why the general circulation of the atmosphere adjusts to the external $\mathrm{CO}_{2}$ forcing. The methodology used in this study allows for a step-bystep assessment of the cause and effect of the changes in the circulation that occur in response to increased greenhouse warming.

The model description and experiment design were presented in Wu et al. (2012, hereafter Part I), which is Part I of this two-part study. Part I made use of a pair of 
"time-slice" experiments: one "reference" experiment with prescribed $\mathrm{CO}_{2}$ concentration of the present day (355 ppmv), named $1 \mathrm{CO}_{2}$ hereafter, and one "doubled$\mathrm{CO}_{2}$ " experiment in which the $\mathrm{CO}_{2}$ concentration is instantaneously and uniformly doubled in the whole atmosphere (710 ppmv) starting from 1 January to focus primarily on the Northern Hemisphere winter zonal jet and storm track transient response, named $2 \mathrm{CO}_{2}$ hereafter. Both the $1 \mathrm{CO}_{2}$ and $2 \mathrm{CO}_{2}$ experiments were integrated for 22 years until reaching equilibrium. Also both of the two experiments have an ensemble of 100 runs, each generated with slightly perturbed initial conditions on 1 January. To minimize the model's internal variability, the doubling $\mathrm{CO}_{2}$ response is defined as the difference between the $2 \mathrm{CO}_{2}$ and $1 \mathrm{CO}_{2}$ experiments for the average of the 100 ensemble members. In Part I it was demonstrated that, after the instantaneous $\mathrm{CO}_{2}$ doubling, the $2 \mathrm{CO}_{2}$ simulations approximately reach equilibrium after about 20 years of model integration and that the equilibrium responses resemble those from the CMIP3/ IPCC AR4 coupled climate models under the A1B global warming scenario. In fact, in our simulations, most of the features, such as the structure of the enhanced tropical and subtropical upper tropospheric warming and the poleward shift of the tropospheric jets and the midlatitude storm tracks, are well established after a few months of model integration.

One of the key foci in Part I was determining what causes the expansion of the upper tropospheric warming into the subtropics. It has been widely recognized that the extensive warming in the upper troposphere is closely related to the circulation changes in the midlatitudes such as the poleward shift of the tropospheric jet streams and transient eddies (e.g., Wu et al. 2011; O'Gorman 2010; Butler et al. 2010; Riviére 2011). Some studies even assumed the broad upper tropospheric warming as the cause of the circulation change (Butler et al. 2010; Riviére 2011). Whether this is true or not was investigated by looking into the zonal mean temperature tendency (diabatic versus adiabatic) in our instantaneous $\mathrm{CO}_{2}$ doubling experiments. In Part I it was shown that the upper tropospheric warming expansion into the subtropics is, in fact, a consequence of the circulation change (rather than the cause) and is primarily dynamically driven by the intensification of transient eddy momentum flux convergence and resulting anomalous descending motion in this region.

In addition, Part I also analyzed the day-by-day response of the zonal mean zonal wind and it was shown that the poleward displacement of the tropospheric jets occurs after the intensification of the subpolar westerlies in the stratosphere and the enhancement of the tropospheric transient eddy momentum flux convergence. This "downward migration" process is similar to that of
Baldwin and Dunkerton (2001), who demonstrated, using reanalysis data, that extreme events in the stratosphere are followed by anomalous weather regimes in the troposphere. This similarity suggests the importance of the stratosphere and its coupling with the troposphere in the circulation adjustment in our model simulations. As for global warming, a number of studies have suggested that the tropospheric circulation response to increased abundance of GHGs critically depends on the stratosphere and its dynamical interaction with the troposphere. For example, Sigmond et al. (2004) studied the separate climatic impacts of middle-atmospheric and tropospheric $\mathrm{CO}_{2}$ doubling using the European Centre Hamburg Model middle atmosphere climate model with prescribed sea surface temperatures (SSTs). They found strengthened Northern Hemisphere (NH) tropospheric westerlies as a consequence of a uniform $\mathrm{CO}_{2}$ doubling everywhere in the atmosphere and attributed this mainly to the middle atmosphere $\mathrm{CO}_{2}$ doubling (see their Fig. 6). Sigmond and Scinocca (2010) found, using the operational version of the Canadian Centre for Climate Modeling and Analysis third-generation atmospheric general circulation model, that different stratospheric basic states, controlled by different parameterization settings of orographic gravity wave drag, can result in distinct $\mathrm{NH}$ circulation responses to $\mathrm{CO}_{2}$ increase.

Figures $1 \mathrm{a}$ and $1 \mathrm{~b}$ show the zonal mean zonal wind anomaly when the tropospheric jet shift first occurs in March of year 1 and in March of year 22 (the equilibrium state), respectively, from the instantaneous $\mathrm{CO}_{2}$ doubling experiment with the NCAR CAM3-SOM. The zonal wind responses between the transient and equilibrium states share many similarities in the $\mathrm{NH}$ extratropical atmosphere such as the westerly intensification in the stratosphere and the midlatitude jet shift in the troposphere. This suggests the importance of the transient state in setting up the extratropical circulation anomalies to global warming. Features such as the westerly anomalies in the $\mathrm{NH}$ subtropical upper troposphere and in the Southern Hemisphere (SH) develop later. Figure 1c also shows the zonal wind anomalies for anthropogenic climate change in March as represented by the average of 22 CMIP3/IPCC AR4 coupled climate models. ${ }^{1}$ These

${ }^{1}$ All 24 CMIP3/IPCC AR4 coupled climate models were included except for the UKMO Hadley Centre Global Environmental Model version 1(HadGEM1; no available output at $10 \mathrm{mb}$ ) and the Meteorological Institute University of Bonn (MIUB) ECHAM and the global Hamburg Ocean Primitive Equation (ECHO-G; no available output above $100 \mathrm{mb}$ ). The global warming response is calculated as the difference between the 2081-2100 A1B scenario and 1961-2000 in the twentiethcentury simulation. 

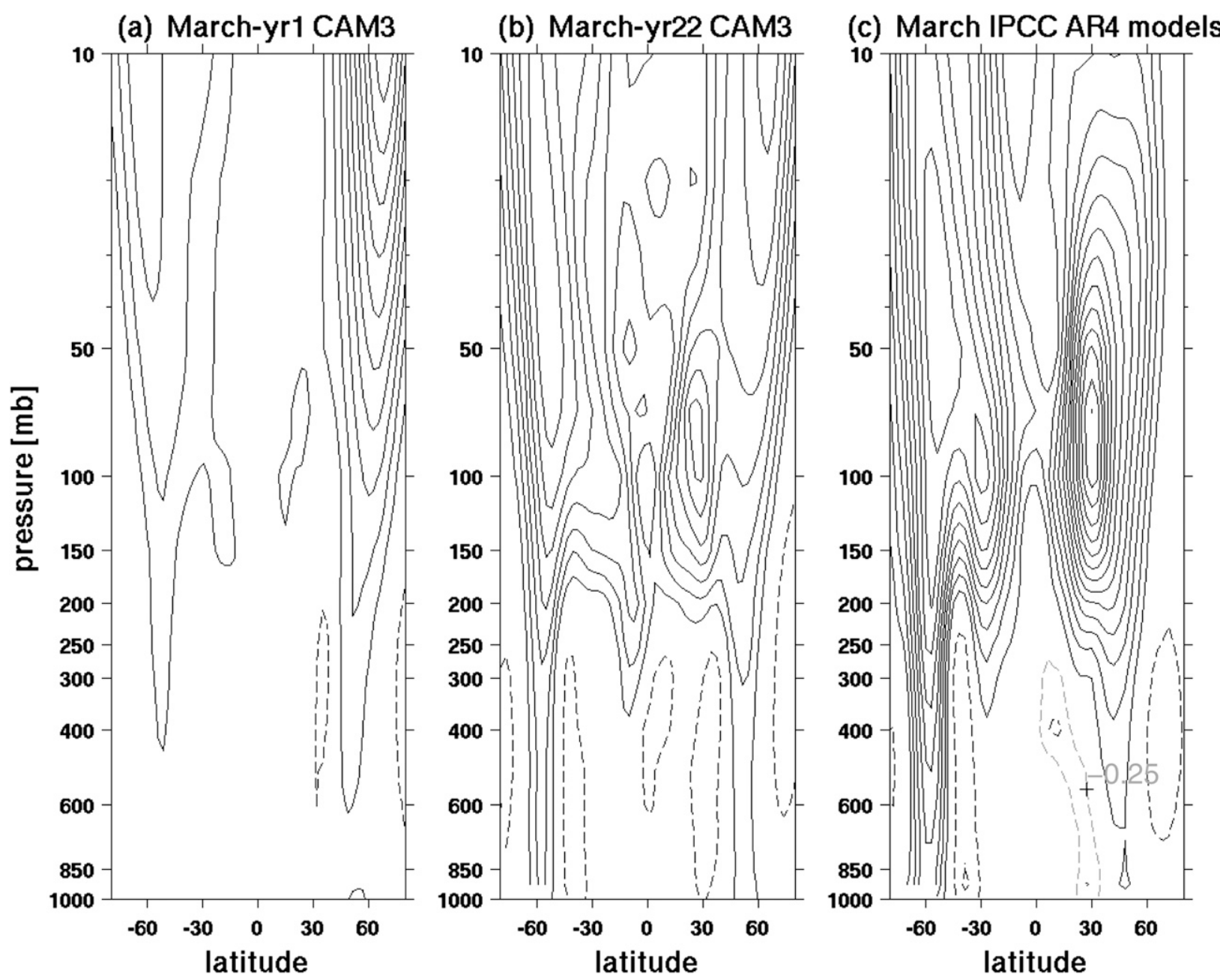

FIG. 1. The zonal mean zonal wind anomalies in (a) March of year 1 (transient), (b) March of year 22 (equilibrium) from the instantaneous $\mathrm{CO}_{2}$ doubling experiment with the CAM3-SOM, averaged over 100 ensemble runs, and (c) March averaged over 22 CMIP3/ IPCC AR4 coupled models (see text). Black solid (black dashed) contours indicate positive (negative) values with contour intervals (CIs) of $0.5 \mathrm{~m} \mathrm{~s}^{-1}$. To better display the zonal wind shift in the troposphere (the "dipole" structure) for (c), the $-0.25 \mathrm{~m} \mathrm{~s}^{-1}$ contour is included and is plotted as a gray dashed line.

also show a westerly intensification in the stratosphere and a poleward shift of the tropospheric jet streams, in agreement with the results from the CAM3-SOM. Hence understanding the mechanisms of stratospheretroposphere coupling in CAM3-SOM may be of relevance to other climate models.

Figure 2 is the same as Fig. $7 \mathrm{~b}$ in Part I and shows the day-by-day evolution of the zonal mean zonal wind response averaged in the $\mathrm{NH}$ extratropics between $30^{\circ}$ and $70^{\circ} \mathrm{N}$ during January-April (JFMA) of year 1 averaged across the 100 ensemble members. It shows that the tropospheric jet shift takes place in early March and is preceded by anomalous westerlies in the stratosphere. Before discussing the dynamics, we demonstrate here that an ensemble of 100 runs is large enough to produce the key features in Fig. 2. We calculate the standard deviations $(\sigma)$ of the zonal mean zonal wind anomalies among the 100 ensemble members. We then define that the zonal wind anomalies are of statistical significance if $|\mu| \geq 2(\sigma / \sqrt{n})$, where $\mu$ denotes ensemble-mean anomalies and $n=100$ is the number of ensemble runs. In Fig. 2, major features such as the stratospheric westerly anomalies and the tropospheric jet shift starting from early March and persisting into April are statistically significant.

Based on Fig. 2, we define three phases during this 120-day transient adjustment in the NH extratropics. Phase 1 roughly covers the first month after the instantaneous doubling of $\mathrm{CO}_{2}$ on 1 January and shows an easterly anomaly in the subpolar stratosphere. Phase 2 


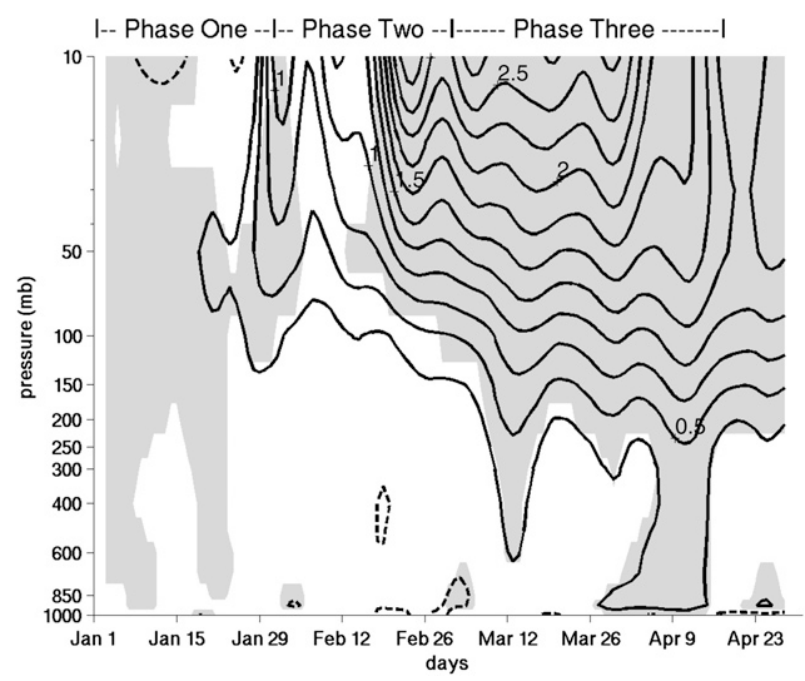

FIG. 2. Day-by-day evolution of the zonal mean zonal wind anomalies averaged over $30^{\circ}-70^{\circ} \mathrm{N}$ as a function of day and pressure level during January-April (JFMA) in year 1, averaged over 100 ensemble runs. A 5-day running average is applied in plotting. Gray shadings indicate statistical significance (see text). Three phases are defined during this transient adjustment process. The contour intervals are $0.25 \mathrm{~m} \mathrm{~s}^{-1}$. This figure is the same as Fig. $7 \mathrm{~b}$ in Part I except for the significance.

presents a transition into a westerly anomaly in the stratosphere that takes place in February. Phase 3 occurs during March and April and features a downward migration of the westerly anomalies from the lower stratosphere to the troposphere and a poleward displacement of the tropospheric jet. In this paper, we analyze the dynamical mechanisms involved in each of the three phases, particularly what drives the easterly (westerly) anomalies in the stratosphere in phase 1 (phase 2) and what causes the descent of the anomalous westerlies from the lower stratosphere to the troposphere and leads to the poleward displacement of the tropospheric zonal jets in phase 3. There are several mechanisms that have been proposed to understand the tropospheric circulation shift in response to global warming such as the increase in eddy phase speed (Lu et al. 2008; Chen et al. 2008), the rise in tropopause height (Lorenz and DeWeaver 2007), and the increase in eddy length scale (Kidston et al. 2010, 2011). We examine all the above proposed mechanisms using our model simulations in order to assess whether or not they can explain the circulation changes seen in the experiments. This analysis provides a unified assessment of the possible mechanisms within the same framework.

In section 2 we introduce the diagnostic methodologies that have been used in this study. Section 3 presents aspects of the climatological simulation results from the CAM3-SOM experiments. Section 4 analyzes the dynamical mechanisms underlying each of the three phases during the transient adjustment process. Conclusions and discussions are presented in section 5.

\section{Diagnostic methodologies}

\section{a. Eliassen-Palm flux and its divergence}

The quasigeostrophic (QG) Eliassen-Palm (EP) flux in spherical and pressure coordinates is defined as

$$
\begin{aligned}
& F_{(\phi)}=-a \cos \phi(\langle u v\rangle-\langle u\rangle\langle v\rangle), \\
& F_{(p)}=a f \cos \phi \frac{\langle v \theta\rangle-\langle v\rangle\langle\theta\rangle}{\langle\theta\rangle_{p}},
\end{aligned}
$$

where $f$ is the Coriolis parameter and $\theta$ is potential temperature (Edmon et al. 1980). Eddy momentum flux and heat flux are denoted by $\langle u v\rangle-\langle u\rangle\langle v\rangle$ and $\langle v \theta\rangle-$ $\langle v\rangle\langle\theta\rangle$, respectively, which include both transient and stationary waves, where the angle brackets in this study follow the same notation as in Part I and denote zonal averages. The direction of the flux vectors, $\left[F_{(\phi)}, F_{(p)}\right]$, generally indicates the propagation of waves and the flux divergence, denoted by $(1 / a \cos \phi) \nabla \cdot \mathbf{F}=(1 / a \cos \phi)$ $\left\{(1 / a \cos \phi)(\partial / \partial \phi)\left[F_{(\phi)} \cos \phi\right]+(\partial / \partial p) F_{(p)}\right\}$, measures the wave forcing on the zonal mean flow. It is noted that the EP flux vectors in this study are all normalized by the basic-state density as in Edmon et al. (1980) to better display the wave activity in the stratosphere unless otherwise specified.

\section{b. Spectral and cross-spectral analysis}

To identify the dominant waves during the transient adjustment process, the EP flux is decomposed into different zonal wavenumbers as follows:

$$
\begin{gathered}
u(\lambda)-\langle u\rangle \stackrel{\mathrm{FT}}{\longrightarrow} \sum_{k=0}^{k_{\max }} \hat{u}(k), \\
(u-\langle u\rangle)(v-\langle v\rangle) \stackrel{\mathrm{FT}}{\longrightarrow} 2 \operatorname{Re} \sum_{k=0}^{k_{\max }} \hat{u}(k) \hat{v}^{*}(k),
\end{gathered}
$$

where $\lambda$ is longitude and $k$ is zonal wavenumber. Here $\hat{u}(k)[\hat{v}(k)]$ is the Fourier transform (FT) of the zonal (meridional) eddy velocity and $\hat{v}^{*}(k)$ denotes the complex conjugate of $\hat{v}(k)$. The same methodology applies to the meridional heat flux.

In addition, following Randel and Held (1991), a phase speed spectrum for eddy momentum flux convergence is computed. We first compute the zonal wavenumber $(k)$-frequency $(\nu)$ cospectra of $(u, v)$ using the daily $u$ and $v$ data. The wavenumber $(k)$-angular 
phase speed $\left(C_{p, a}\right)$ cospectra is then defined and transformed from the $k-\nu$ cospectra by conserving the total power of momentum flux convergence, where $C_{p, a}$ here is defined as $C_{p, a}=(\nu a \cos \phi / k)$. Finally the phase speed spectrum of momentum flux convergence is constructed by summing over all the zonal wavenumbers and is plotted as a function of latitude and angular phase speed.

\section{c. Linear quasigeostrophic refractive index}

The index of refraction is a useful predictor and diagnostic for the propagation of planetary waves and has been widely used in various climate states to help interpret the behavior of waves and their interaction with the mean flow (e.g., Charney and Drazin 1961; Matsuno 1970).

Matsuno (1970) provided an analytical formula for the stationary linear refractive index by assuming that the atmosphere is isothermal (and thus has constant buoyancy frequency, $N$ ). This assumption is a reasonable approximation for the stratosphere but not for the troposphere. For a nonisothermal atmosphere, the zonal mean refractive index for waves with a zonal wavenumber $k$ and a speed $C_{p}$ is written as

$$
\begin{aligned}
n_{\mathrm{ref}}^{2}= & \frac{a\left\langle q_{\phi}\right\rangle}{\langle u\rangle-C_{p}}-\frac{k^{2}}{\cos ^{2} \phi}-\frac{f^{2} a^{2}}{4 N^{2} H_{o}^{2}}, \\
\left\langle q_{\phi}\right\rangle= & 2 \Omega \cos \phi-\frac{\partial}{\partial \phi}\left(\frac{1}{a \cos \phi} \frac{\partial\langle u\rangle \cos \phi}{\partial \phi}\right) \\
& +\frac{f^{2} a}{R} \frac{\partial}{\partial p}\left(\frac{p\langle\theta\rangle}{\langle T\rangle} \frac{\langle u\rangle_{p}}{\langle\theta\rangle_{p}}\right),
\end{aligned}
$$

where $R_{d}$ is the dry air gas constant $\left(287 \mathrm{~J} \mathrm{~kg}^{-1} \mathrm{~K}^{-1}\right), q_{\phi}$ is the meridional potential vorticity (PV) gradient and $H_{o}$ is the scale height of pressure $\left(H_{o}=7 \mathrm{~km}\right)$. Note that $n_{\mathrm{ref}}^{2}$ is dimensionless in Eq. (5).

In addition, we also make use of a linear QG model to diagnose the wave propagation characteristics of a two-dimensional zonal mean basic state (Harnik and Lindzen 2001). The model takes the zonal mean zonal wind and temperature with a specified eddy phase speed $C_{p}$ and zonal wavenumber $k$ and solves the conservation of the QGPV equation. The model outputs the eddy fluxes, the index of refraction, and its separation into terms related to the squares of the vertical $\left(\mathrm{m}^{2}\right)$ and meridional wavenumbers $\left(l^{2}\right): n_{\text {ref }}^{2}=m^{2}+\left(N^{2} / f^{2}\right) l^{2}$. Studies have found that $l^{2}$ and $m^{2}$ serve as more accurate indicators of wave propagation in the vertical and meridional directions (e.g., Harnik and Lindzen 2001; Perlwitz and Harnik 2003; Shaw et al. 2010). Waves propagate in the meridional (vertical) direction where $l^{2}>0\left(m^{2}>0\right)$, are evanescent where $l^{2}<0\left(m^{2}<0\right)$, are reflected where $l^{2}=0\left(m^{2}=0\right)$, and are absorbed where $l^{2} \rightarrow \infty\left(m^{2} \rightarrow \infty\right)$ as for the index of refraction.

\section{Climatological CAM3-SOM simulations}

This section compares the climatological simulations of the zonal mean zonal wind and wave activities in the Northern Hemisphere winter using the CAM3-SOM against the latest reanalysis dataset from the European Centre for Medium-Range Weather Forecasts (ECMWF), which has a good representation of the stratosphere (e.g., Seviour et al. 2011). The interim ECMWF Re-Analysis (ERA-Interim; Dee et al. 2011) data are available over the period 1979-2010 and its atmospheric model has 60 model layers in the vertical with the top located at $0.1 \mathrm{mb}$. By comparison, the NCAR CAM 3 has 26 vertical layers with a model top at $2.9 \mathrm{mb}$. As shown later, the CAM3 does not have a good simulation of the stratospheric circulation in $\mathrm{NH}$ winter, probably because of the low model top.

Figure 3 a shows the climatological zonal mean zonal wind, EP flux, and its divergence calculated from the ERA-Interim daily variables for February. ${ }^{2}$ The flux vectors clearly indicate that the waves are generated in the lower troposphere, presumably by the orographic forcing and large-scale zonally asymmetric diabatic heating, and propagate upward into the stratosphere. Figure $3 \mathrm{c}$ shows the contributions from the planetary waves including wave 1 and wave 2 , and the similarity in the stratosphere between Figs $3 \mathrm{a}$ and $3 \mathrm{c}$ indicates the dominance of the planetary-scale long waves in the stratosphere, consistent with the theoretical work of Charney and Drazin (1961). In addition, these upward propagating Rossby waves in the extratropics are always refracted equatorward toward the critical layer where the eddy phase speed equals the zonal mean flow velocity and the waves are absorbed. In addition, maxima in EP flux convergence (i.e., $(1 / a \cos \phi) \boldsymbol{\nabla} \cdot \mathbf{F}<0)$ in general occur in regions where waves are absorbed or dissipated-for example, north of the subtropical critical layer, in the high-latitude middle troposphere and in the high latitudes below the polar jet (shown in Fig. 3a). In particular, the net convergence of EP flux in the highlatitude stratosphere is consistent with the BrewerDobson circulation with upwelling in the tropics and poleward and downward motion at high latitudes.

\footnotetext{
${ }^{2}$ February is chosen here for a better comparison with the anomalies in February from the model simulations to be shown later. The climatological features in February are generally similar to December-February averages.
} 

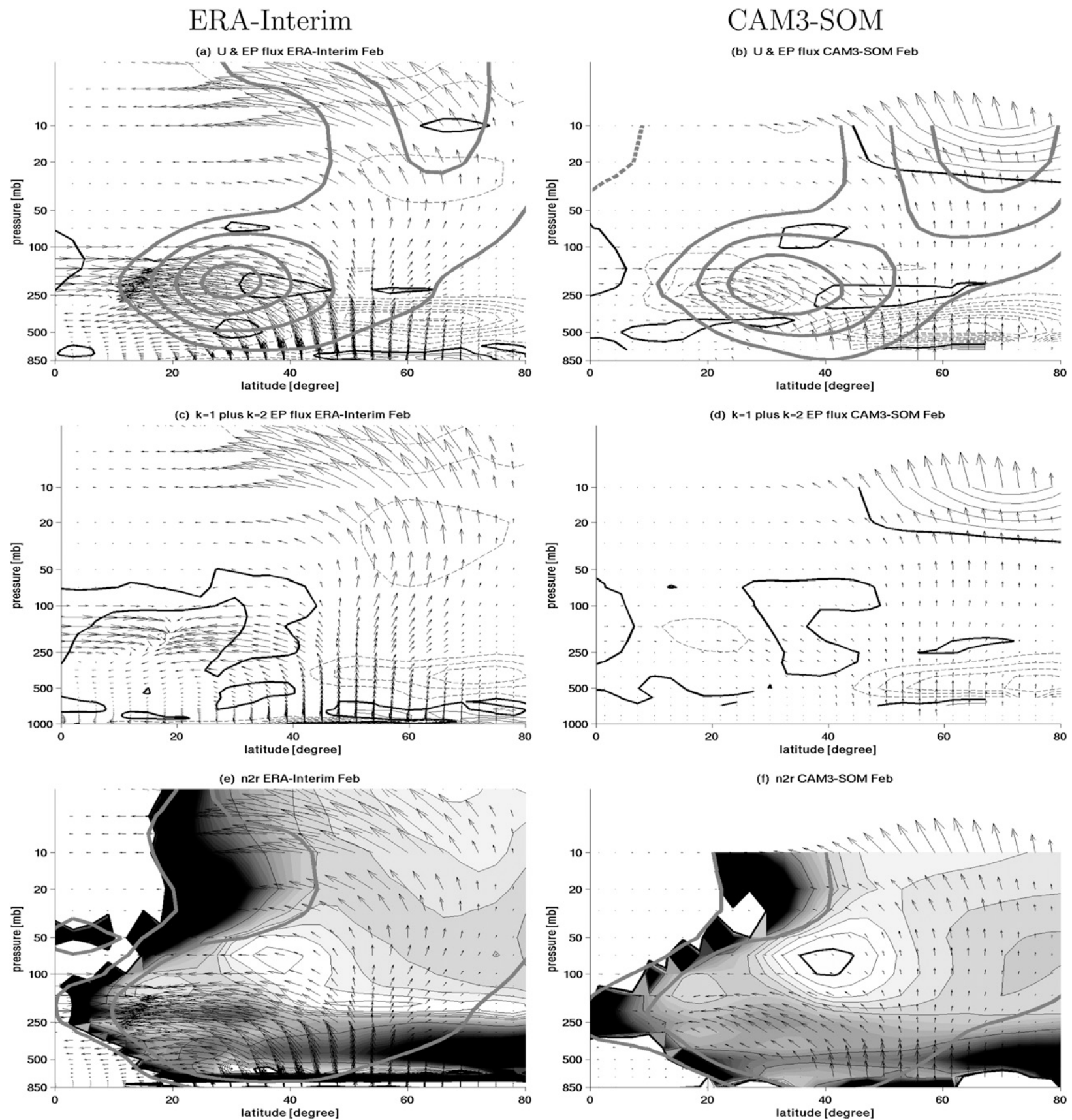

FIG. 3. Comparison of circulation climatologies in the (left) ERA-Interim Reanalysis dataset and (right) CAM3-SOM simulations for February. (a),(b) The zonal mean zonal wind (thick gray contours with contour intervals of $10 \mathrm{~m} \mathrm{~s}^{-1}$ ), the EP flux, and its divergence (black contours with CIs of $2 \mathrm{~m} \mathrm{~s}^{-1} \mathrm{day}^{-1}$ ). (c),(d) The EP flux and its divergence from wave 1 plus wave 2. (e),(f) The calculated index of refraction $n_{\text {ref }}^{2}$ (unitless) in black contours and shadings with darker colors showing larger values. The zero and $8 \mathrm{~m} \mathrm{~s}^{-1}$ zonal wind lines are highlighted in thick gray contours.

However, as shown in Figs. $3 b$ and 3d, the CAM3SOM fails to capture the convergence in the highlatitude stratosphere correctly and instead produces a net divergence of EP flux (i.e., $(1 / a \cos \phi) \nabla \cdot \mathbf{F}>0)$. This is a result of both the amplification of the momentum flux and underestimation of the heat flux near the model lid of the CAM3 (not shown). The net divergence of EP flux is, in part, balanced by the Coriolis torque and imposes an unrealistic westerly acceleration tendency in the polar stratosphere, explaining the stronger stratospheric 
polar jet in the model simulations than in the reanalysis (shown in Figs. 3a,b).

Upper boundary conditions are commonly applied in general circulation models and, as above, the model lid in the CAM3 is at about $2.9 \mathrm{mb}$ where the vertical velocity is assumed zero. The effects of this artificial upper boundary on climate model simulations have been long recognized (e.g., Boville 1984; Boville and Cheng 1988; Shaw and Perlwitz 2010; Sassi et al. 2010). The model's upper boundary condition leads to reflection of vertically propagating planetary-scale wave activity, changes the meridional/vertical phase structures, causes increased (decreased) poleward eddy momentum (heat) flux, and results in a net westerly forcing on the zonal mean flow (Boville and Cheng 1988; Sassi et al. 2010). Sassi et al. (2010) compared the present-day simulations between the CAM3 and the Whole Atmosphere Community Climate Model version 3 (WACCM3) (its vertical domain extends to $5.9 \times 10^{-6} \mathrm{mb}$ ) and found substantial differences in the zonal mean state of the stratosphere and the behavior of the stratospheric variability. In particular, they demonstrated that the amplification of the momentum flux and the reduction of the heat flux near the model lid of the CAM3 coincided with the region of wave reflection in the highlatitude stratosphere [see Figs. 4 and 5 in Sassi et al. (2010)]. Thus, CAM3 does not properly simulate stratospheric dynamics and this suggests caution in interpreting the circulation behavior in the CAM3$\mathrm{SOM}$ as a consequence of $\mathrm{CO}_{2}$ doubling and its relevance to the real world. However, with this in mind, our goal here is to explain the circulation response in the CAM3 as a representative of typical state-of-theart IPCC AR4 models that predict a poleward shift of the tropospheric jet in response to increased $\mathrm{CO}_{2}$ (see Fig. 1).

Figure $3 \mathrm{e}$ and $3 \mathrm{f}$ show the index of refraction $n_{\text {ref }}^{2}$ for planetary-scale stationary waves in the stratosphere with $k=1$ and $C_{p}=0$ following Eq. (5). The index of refraction is positive almost everywhere in the extratropics except for the region of minimum values in the midlatitude lower stratosphere at about $40^{\circ} \mathrm{N}$ between 70 and $100 \mathrm{mb}$ (shown in Figs. 3e,f). Matsuno (1970) noted the significance of this minimum in the index of refraction and argued that it creates a partial waveguide for vertical propagation on its poleward side. In addition, the $n_{\text {ref }}^{2}$ increases almost monotonically from high to low latitudes and becomes infinitely large as the waves reach the zero wind line (critical layer), which is highlighted in thick gray in Figs. $3 e$ and 3f. The disagreement of the EP flux and its divergence between the reanalysis and the model simulations in the stratosphere above $50 \mathrm{mb}$ suggests that the index of refraction cannot be used to understand wave propagation at those heights in the CAM3 model. The ERA-Interim reanalysis model lid and vertical resolution in the stratosphere are sufficient to resolve the planetary wave-mean flow interaction; however, they are not adequate in the CAM3 model. Nonetheless, the index of refraction can be used in the troposphere in the CAM3 to explain wave propagation. The EP flux vectors in the troposphere generally follow the gradients of $n_{\text {ref }}^{2}$, and the waves are indeed refracted equatorward toward increasing $n_{\text {ref }}^{2}$.

\section{Three-phase atmospheric transient circulation adjustment process}

The three phases of the circulation response occur during January-April in year 1 . At the end of this transient adjustment process, the extratropical circulation response resembles that in the equilibrium state and the tropospheric jet streams are shifted poleward. Figure 4 shows the latitude-pressure level plot of the zonal mean zonal wind and temperature anomalies in phase 1 (January), 2 (February), and 3 (March and April), respectively. The climatological zonal mean zonal wind and temperature on 1 January are also shown in Fig. 4 (first row) for reference. In the following we discuss the dynamical mechanisms involved in each of the three phases.

\section{a. Phase 1 (January): Stratospheric subpolar easterly anomaly}

An easterly anomaly in the high-latitude stratosphere, together with a westerly anomaly in low latitudes, occurs in the first few days after the instantaneous doubling of $\mathrm{CO}_{2}$ on 1 January. This is a fast purely radiatively driven response and the zonal mean temperature anomaly generally follows the longwave radiation anomaly in the stratosphere (not shown). The stratosphere cools with increased $\mathrm{CO}_{2}$ and emits increased longwave radiation out to space. In general, with a uniform $\mathrm{CO}_{2}$ increase, the stratosphere cools due to blackbody radiation more (less) where the control temperature is warmer (colder). As shown in Fig. 4a, the NH control temperature in the stratosphere increases with latitude but only to the midlatitudes and then decreases toward the North Pole where there is no incoming solar radiation. The radiative response basically follows the control temperature structure in the stratosphere, with more longwave radiation emitted out to space in the northern middle latitudes, causing maximum cooling there and generating a poleward (equatorward) flow and a westerly (easterly) anomaly in the low (high)-latitude stratosphere due to geostrophic adjustment (shown in Figs. 4c,d). In phase 1 
$\mathrm{T}$

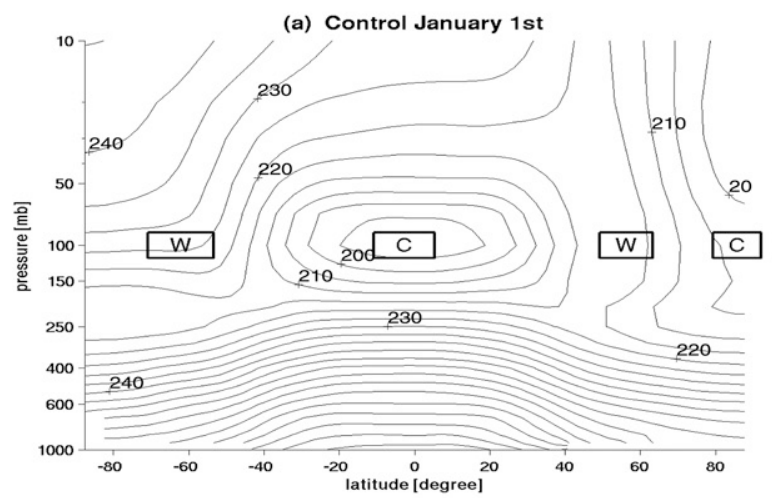

(c) Phase One - January

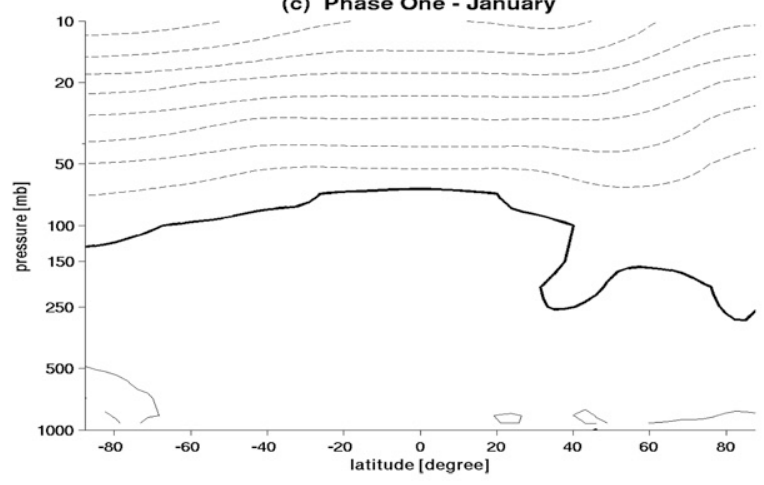

(e) Phase Two - February

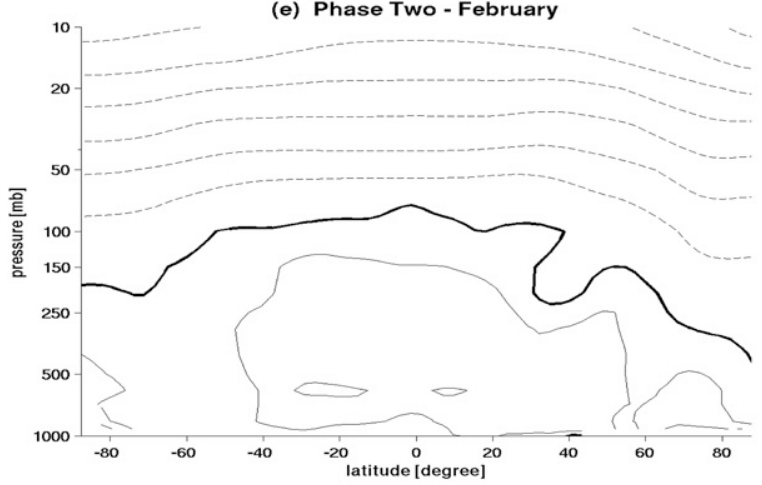

(g) Phase Three - March and April

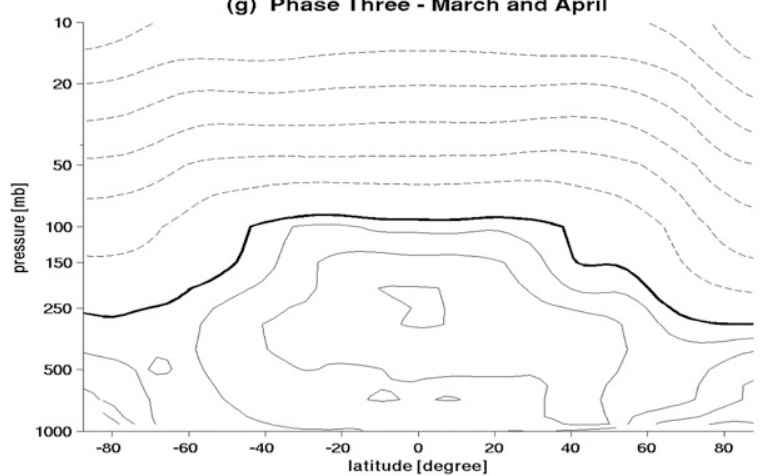

$\mathrm{U}$

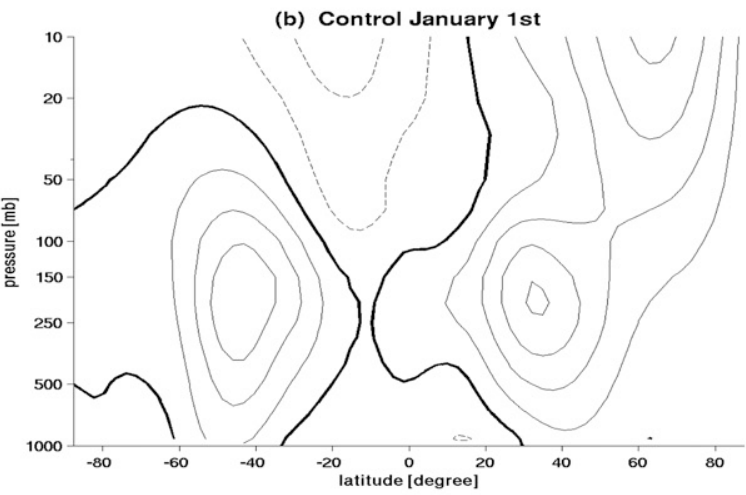

(d) Phase One - January
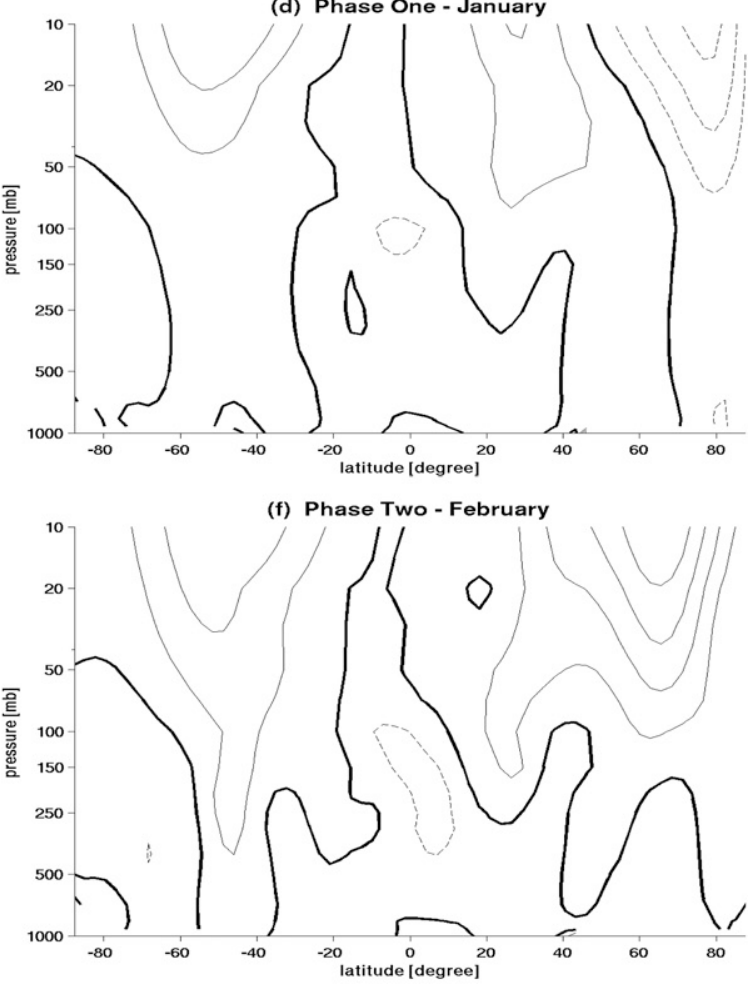

(h) Phase Three - March and April

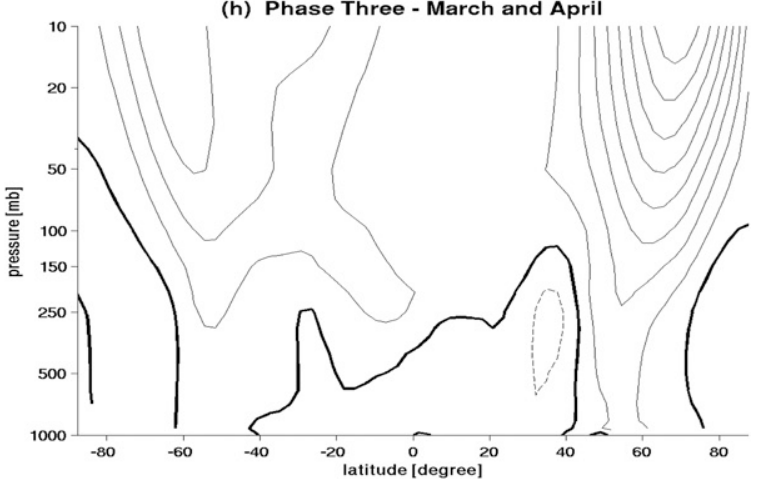

FIG. 4. (a),(b) Climatological zonal mean zonal wind and temperature on 1 January, and their anomalies in phases (c),(d) 1, (e),(f) 2, and (g),(h) 3. The contour intervals are $5 \mathrm{~K}$ for (a), $10 \mathrm{~m} \mathrm{~s}^{-1}$ for (b), $+0.25 \mathrm{~K}(-0.5 \mathrm{~K})$ for (c), $0.25 \mathrm{~m} \mathrm{~s}^{-1}$ for $(\mathrm{d}),+0.25 \mathrm{~K}(-1 \mathrm{~K})$ for $(\mathrm{e})$ and (g), and $0.5 \mathrm{~m} \mathrm{~s}^{-1}$ for (f) and (h). 

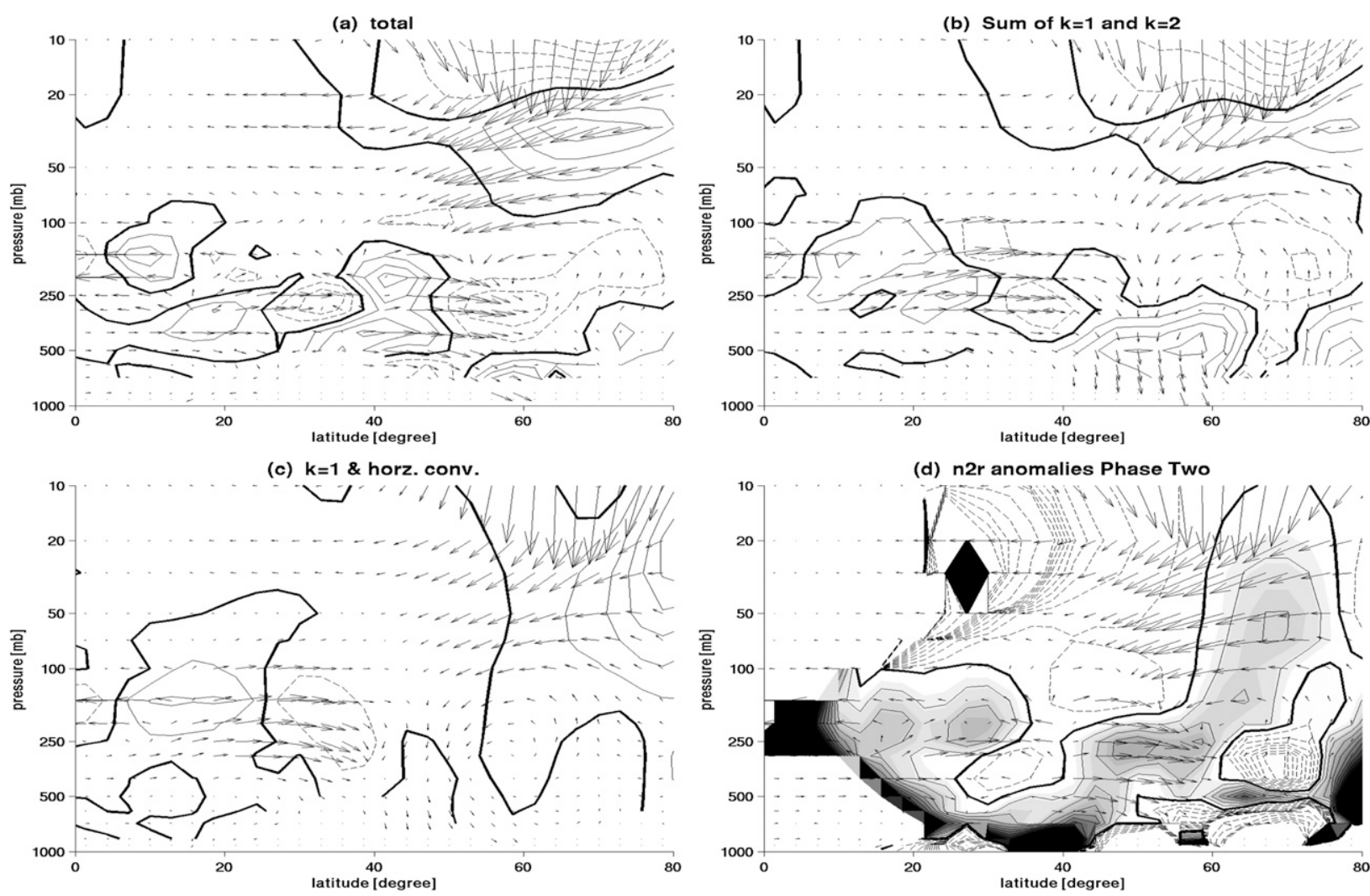

FIG. 5. Anomalies of EP flux and its divergence in phase 2 (February) for (a) all waves and (b) wave 1 plus wave 2. (c) The anomalies for wave 1 and their horizontal divergence of EP flux. (d) The changes in refractive index $n_{\mathrm{ref}}^{2}$ and total EP flux anomalies. Solid contours and shadings denote positive changes in $n_{\text {ref }}^{2}$ while dashed contours show negative changes. The contour intervals for (a)-(c) are $0.1 \mathrm{~m} \mathrm{~s}^{-1} \mathrm{day}^{-1}$.

the circulation response is primarily located in the stratosphere.

The radiative response in the $\mathrm{SH}$ is different from that in the $\mathrm{NH}$ because of the difference in control temperature. Here the stratospheric control temperature has a minimum at the equator and monotonically increases toward the South Pole as a consequence of absorption of incoming solar radiation by the ozone during austral summer. This reversed temperature gradient in the stratosphere is consistent with the climatological easterlies in southern summer (shown in Fig. 4b). After the $\mathrm{CO}_{2}$ concentration is increased, the $\mathrm{SH}$ stratosphere cools most at the pole and least at the equator, reducing the meridional temperature gradient causing a poleward flow and a westerly zonal wind anomaly. Because of the weak planetary wave forcing in the southern summer, the stratospheric circulation response is primarily controlled by the radiative forcing until the zonal wind anomaly penetrates into the upper troposphere/lower stratosphere where the transient eddies are expected to respond and impact the whole troposphere. In contrast, the upward propagating planetary wave activity in the
$\mathrm{NH}$ modulates the stratospheric circulation as discussed below.

\section{b. Phase 2 (February): Acceleration of stratospheric westerly anomalies}

In February there is a westerly anomaly in the $\mathrm{NH}$ stratosphere that is consistent with further cooling in the subpolar stratosphere (shown in Figs. 4e,f). A diagnosis of the EP flux and zonal mean zonal momentum equation indicates that the acceleration of the westerly anomaly in the stratosphere is mainly eddy-driven. Figure 5a shows the EP flux anomaly in phase 2 and the combined contribution from planetary wave 1 and wave 2 is shown in Fig. 5b. The agreement between Figs. 5a and 5b indicates that the dominant waves controlling the anomalies in phase 2 are of planetary scale too. Figure $5 \mathrm{c}$ shows the EP flux anomalies from wave 1 and its associated horizontal divergence. It is found that the acceleration of the westerly anomaly in the stratosphere in phase 2 is primarily caused by the increased momentum flux convergence from planetary wave 1 as a result of increased equatorward wave propagation (as shown in Fig. 5c). 
To understand why more planetary waves are refracted equatorward as a consequence of the $\mathrm{CO}_{2}$ increase, the index of refraction $n_{\text {ref }}^{2}$ is computed, the anomaly of which is shown in Fig. $5 \mathrm{~d}$ for $C_{p}=0 \mathrm{~m} \mathrm{~s}^{-1}$ superimposed with the corresponding total EP flux anomalies during phase 2. The largest equatorward wave refraction occurs in the midlatitude stratosphere between about $50^{\circ}$ and $60^{\circ} \mathrm{N}$ whereas the change in $n_{\text {ref }}^{2}$ is positive (negative) on the poleward (equatorward) side. This is not in agreement with predictions of the linear refraction theory.

The reason why stationary eddies refract more equatorward during phase 2 remains unclear. However, as mentioned in the previous section, the index of refraction cannot be used to explain the climatological wave propagation in the stratosphere because it does not properly resolve planetary wave-mean flow interaction because of its low model lid height. It is possible that, in response to $\mathrm{CO}_{2}$ increase, the wave propagation anomalies, in particular near the model top, are also influenced by the model's upper boundary. If this is the case, the wave propagation may not follow the index of refraction since the latter does not account for an upper boundary condition associated with a low model lid. Increased equatorward wave propagation in response to climate change is also found in one of the equilibrium responses to a doubling of $\mathrm{CO}_{2}$ in Sigmond et al. (2008) and Sigmond and Scinocca (2010) [see Figs. 6a,d,g in Sigmond and Scinocca (2010)]. They attributed the enhanced equatorward propagation to the disappearance of the negative $n_{\text {ref }}^{2}$ region in the subtropical lower stratosphere. The region of negative $n_{\text {ref }}^{2}$, however, does not disappear in our simulations.

\section{c. Phase 3 (March and April): Downward migration and poleward displacement of tropospheric jets}

As shown in Fig. 8b in Part I, the tropospheric jet stream starts to shift poleward in early March. This circulation change in the troposphere appears to follow the westerly anomaly acceleration in the stratosphere and the intensification of transient eddy momentum flux convergence in the subtropical middle and upper troposphere (shown in Figs. 7b and 8d in Part I).

Previous studies have proposed hypotheses to explain the tropospheric jet shift in response to global warming. The hypotheses include 1) an increase in eddy phase speed (Lu et al. 2008; Chen et al. 2008), 2) a rise in tropopause height (Lorenz and DeWeaver 2007), and 3) an increase in eddy length scale (Kidston et al. 2011). Another possibility comes from the idea of changing index of refraction, which has been used to understand the transient eddy propagation during El Niños (Seager et al. 2003; Harnik et al. 2010) as well as solar cycles
(Simpson et al. 2009). We analyze each of the above mechanisms and see whether or not they can explain the jet shift that occurs during phase 3 . This study provides a unified assessment of all the proposed mechanisms within the same framework. These mechanisms are evaluated based on the average of 100 ensemble runs. The 100-member ensemble average response was found to be similar to the 50 -member ensemble averaged response (not shown), suggesting the robustness of the results to be shown below.

\section{1) EDDY PHASE SPEED}

Lu et al. (2008) and Chen et al. (2008) identified an increase in eddy phase speed in the GFDL CM2.1 model simulations under the "business-as-usual" A2 scenario in which the $\mathrm{CO}_{2}$ concentration reaches $800 \mathrm{ppmv}$ at the end of the twenty-first century. They argued that this eddy phase speed increase causes the critical line, subtropical breaking region, transient eddy momentum flux convergence, and tropospheric zonal jets to move poleward. Here we follow the computational methodology for the eddy phase speed cross-spectra as in Randel and Held (1991) and Chen and Held (2007) and see whether this hypothesis helps explain the shift in the jet position in our modeling experiments.

Figure 6 shows the cospectra of eddy momentum flux convergence at $250 \mathrm{mb}^{3}$ during the first 120 days of transient adjustment in January-April of year 1 as a function of angular phase speed $\left(C_{p, a}\right)$ and latitude along with the $250-\mathrm{mb}$ zonal wind distribution. The difference between the $2 \mathrm{CO}_{2}$ and the $1 \mathrm{CO}_{2}$ runs is shown in contours while the climatology is shown in color shadings. As expected, the climatological cospectrum shows a divergence in eddy momentum flux in the subtropics and a convergence in the midlatitudes. The $250-\mathrm{mb}$ waves are primarily eastward propagating transient waves with an angular phase speed of about $10 \mathrm{~m} \mathrm{~s}^{-1}$ in the NH. In addition, the meridional wave propagation is confined by the subtropical critical layer, consistent with linear wave refraction theory. The transient anomalies in eddy momentum flux convergence cospectra show a poleward shift in the NH relative to the climatology with an intensification (reduction) on the poleward (equatorward) flank of the climatological maximum position. However, our model experiments with the CAM3-SOM do not show any significant increase in eddy phase speed during the transient adjustment process. The change in zonal mean zonal wind at $250 \mathrm{mb}$ is also small (shown in

\footnotetext{
${ }^{3}$ The value of $250 \mathrm{mb}$ is chosen to be consistent with $\mathrm{Lu}$ et al. (2008). The conclusion does not change when other pressure levels are used.
} 


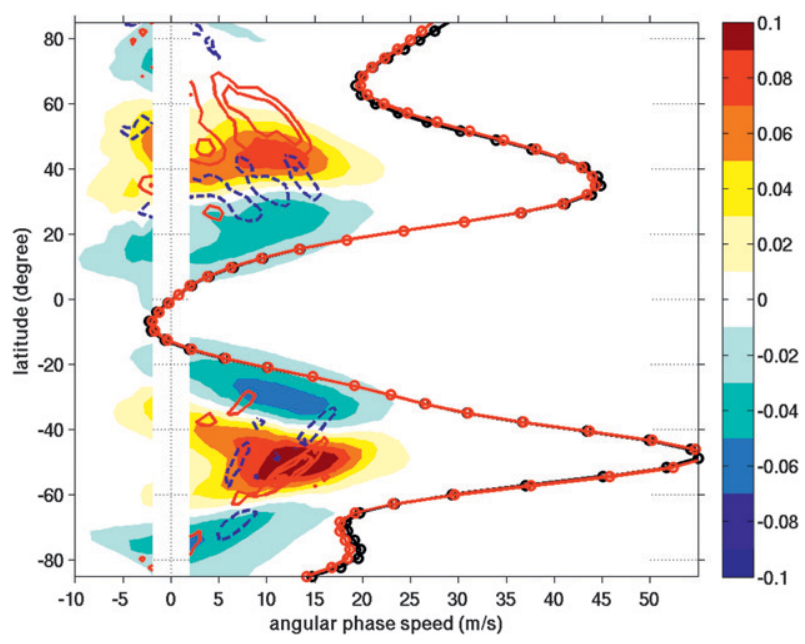

FIG. 6. Cross-spectrum of eddy momentum flux convergence $\left(\mathrm{m} \mathrm{s}^{-1} \mathrm{day}^{-1}\right)$ at $250 \mathrm{mb}$ as a function of angular phase speed $\left(\mathrm{m} \mathrm{s}^{-1}\right)$ and latitude from the CAM3-SOM simulations. Contours show the difference between the $2 \mathrm{CO}_{2}$ and the $1 \mathrm{CO}_{2}$ runs with contour interval of $0.0050 \mathrm{~m} \mathrm{~s}^{-1} \mathrm{day}^{-1}$. Shadings show the results from the $1 \mathrm{CO}_{2}$ runs with positive (negative) values indicating momentum flux convergence (divergence). Black (red) lines show the $250 \mathrm{mb}(u / \cos \phi)$ for the $1 \mathrm{CO}_{2}\left(2 \mathrm{CO}_{2}\right)$ runs. Following Randel and Held (1991), the spectrum is shown for (absolute) angular phase speeds greater than $2 \mathrm{~m} \mathrm{~s}^{-1}$ because lower phase speeds are not resolved.

Fig. 6). In addition, we find no significant increase in eddy phase speed in the equilibrium state either (not shown).

In our simulations, the increase in eddy phase speed is not an explanation for the tropospheric jet shift. It is possible that the increase in eddy phase speed is model dependent. Simpson et al. (2009) investigated the stepby-step adjustment in the tropospheric circulation response to stratospheric heating perturbations using a simple general circulation model. They found no increase in eddy phase speed in their study (see their footnote 2 on p. 1356). Riviére (2011) investigated the effect of changing eddy length scale on wave breaking and resulting changes in jet position, and a slightly decreased phase speed was found during the process.

\section{2) Tropopause height}

As the location of the jet streams and the scale of eddies are closely related to the depth of the troposphere, it is possible that the jet shift could be induced by a change in tropopause height. Since the scale of the eddies is characterized by the Rossby radius, $L_{R}=$ $(N H / f)$, where $H$ denotes the thickness of the troposphere, eddies in theory should become larger as the tropopause height is raised. According to Kidston et al. (2011), the eddy-driven jets are expected to move

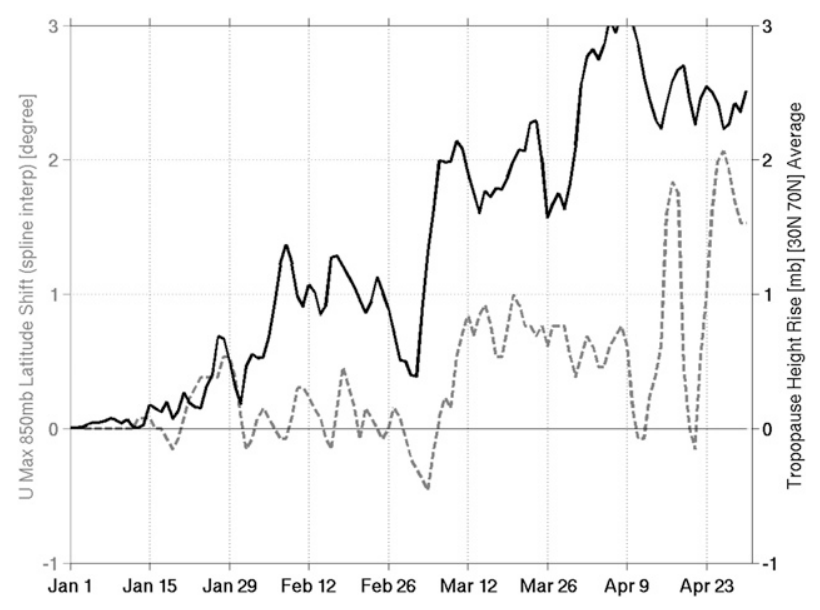

FIG. 7. Day-by-day evolution of the 850 -mb jet position shift (dashed gray line) vs the rise in tropopause height averaged over the midlatitudes between $30^{\circ}$ and $70^{\circ} \mathrm{N}$ (solid black line) during JFMA in year 1. A 3-day running average has been applied to the jet shift.

toward higher latitudes as a consequence of larger eddies by reducing the eddy phase speed relative to the mean flow on the poleward flank of the jets and shifting the dissipation and eddy source regions poleward. Observations indicate that the height of the tropopause has gone up by several hundred meters since 1979 and is closely related to the warming of the troposphere and the poleward expansion of the Hadley cell with anthropogenic forcing implicated as a cause (e.g., Santer et al. 2003; Seidel and Randel 2007; Lu et al. 2009). Lorenz and DeWeaver (2007) found similarities in the extratropical circulation response between IPCC AR4 coupled models (A2 scenario) and a simple dry GCM when the tropopause height is raised (by about $400 \mathrm{~m}$ ), suggesting that the rise in tropopause height is the dominant driver of the extratropical circulation response to global warming, although in their experiments the effect of increasing baroclinic instability in the upper troposphere was not excluded.

Figure 7 shows the day-by-day evolution of the change in the location of the $850-\mathrm{mb}$ midlatitude jet maximum and the rise in tropopause height averaged over the midlatitude region between $30^{\circ}$ and $70^{\circ} \mathrm{N}$. The calculation of tropopause height follows the algorithm in Reichler et al. (2003) and finds the lowest pressure level at which the temperature lapse rate decreases to $2 \mathrm{~K} \mathrm{~km}^{-1}$. Because of the coarse resolution in latitude of CAM3, the zonal mean zonal wind is first interpolated to a finer latitude grid before locating the jet maximum. ${ }^{4}$

\footnotetext{
${ }^{4}$ Cubic spline interpolation is used here but the results do not change much for other interpolation schemes.
} 
As a result of $\mathrm{CO}_{2}$ doubling and the fast radiative stratospheric cooling, the tropopause starts to rise after about 15 days and keeps on rising by about $1 \mathrm{mb}$ before it drops at the end of February. Despite these changes in tropopause height, there is not much change in jet maximum position near the surface. In early March, the tropopause height starts to rise again sharply and this time is followed by a poleward shift in the jet position near the surface with a lag of a few days. This is a robust result for the jets at various vertical levels and for tropopause height at different latitudes. The tropopause, on average, rises by $2 \mathrm{mb}$ while the low-level jet moves by about $1^{\circ} \mathrm{N}$ in March. Although the rise in tropopause height leads the low-level jet shift in early March, there is overall small correlation between the time history of these two quantities. As argued in Kidston et al. (2011), the dynamics connecting the tropopause height rise with the poleward displacement of the tropospheric jet streams is via an increase in eddy length scale, the day-by-day evolution of which is further investigated below.

\section{3) EDDY LENGTH SCALE}

Kidston et al. (2010) found a robust increase in eddy length scale in the A2 scenario simulation of the future climate among an ensemble of CMIP3/IPCC AR4 models. Wu et al. (2011) also noticed this increase in eddy length scale in the Geophysical Fluid Dynamics Laboratory Climate Model version 2.0 (GFDL CM2.1) model under the $\mathrm{A} 1 \mathrm{~B}$ scenario and found that the larger eddies are partially responsible for the increased poleward energy transport carried by the storm tracks in the future climate. Kidston et al. (2011) refined the idea that an increase in eddy length scale can cause the jet streams to move poleward rather than vice versa, which is confirmed in a simple barotropic model experiment. Riviére (2011) emphasized the role of enhanced upper-tropospheric baroclinic instability in the poleward shift of the jet streams via changes in eddy length scale and anticyclonic/ cyclonic wave breaking in the global warming scenario.

Following the methodology in Kidston et al. (2010), we calculate the eddy length scale day by day during the transient adjustment process. The mean eddy length scale is defined as $\bar{L}_{\text {eddy }}=[(2 \pi a \cos \phi) / \bar{k}]$, with $\bar{k}$ measuring the energy weighted zonal wavenumber: $\bar{k}=$ $\left[\left(\sum_{k} k|\hat{v}(k)|^{2}\right) /\left(\sum_{k}|\hat{v}(k)|^{2}\right)\right]$, where $|\hat{v}(k)|^{2}$ denotes the high-pass filtered ${ }^{5}$ meridional component of the eddy kinetic energy in wavenumber $(k)$ space. Figure 8 plots the day-by-day evolution of the change in eddy length scale $\bar{L}_{\text {eddy }}$ averaged over the midlatitudes between $30^{\circ}$

\footnotetext{
${ }^{5}$ The high-pass filter retains synoptic time scales of 2-8 days, and is the same filter that was used in Part I.
}

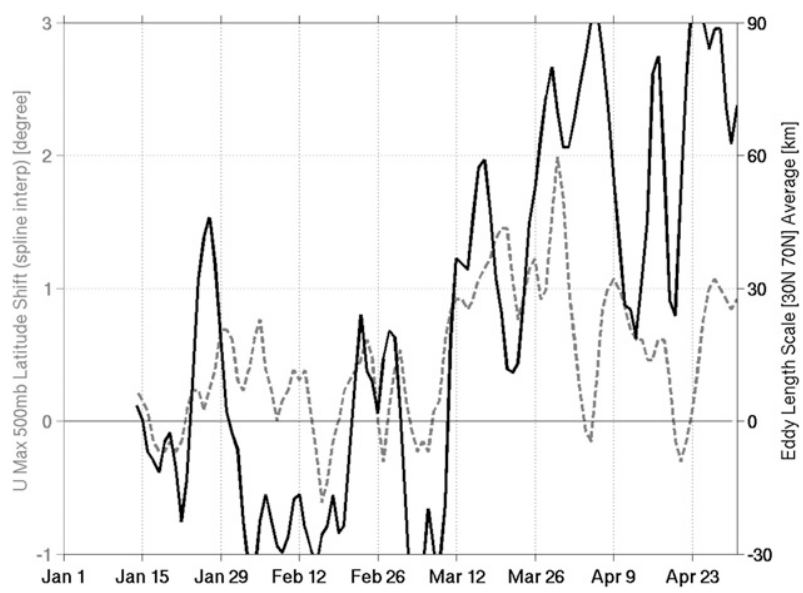

FIG. 8. Day-by-day evolution of the $500-\mathrm{mb}$ jet position shift (dashed gray line) vs the change in eddy length scale averaged over the midlatitudes between $30^{\circ}$ and $70^{\circ} \mathrm{N}$ (solid black line) during January-April in year 1. A 3-day running average has been applied to both the jet shift and the eddy length scale change.

and $70^{\circ} \mathrm{N}$ at $500 \mathrm{mb}$ along with the jet shift at $500 \mathrm{mb}$. The 500-mb jet position change is noisy in January and February but it shifts to higher latitudes in March and April quite persistently. The evolution in eddy length scale is noisy compared with that of the jet shift and tropopause height rise but clearly shows a rapid transition from a negative anomaly to a positive anomaly starting in early March. The increase in eddy length scale on average reaches about $60 \mathrm{~km}$ at the end of March and in April. However, both the increase in eddy length scale and the poleward jet shift start at approximately the same time [i.e., early March (before 12 March)], and the lead-lag relationship between the two is hard to identify and is not statistically significant (not shown).

Since the causality sequence between the eddy length scale increase and the poleward jet shift is hard to identify, the mechanism proposed by Kidston et al. (2011) cannot be confirmed here. In addition, the dynamical mechanisms linking the tropopause height rise and the jet shift remain unclear. In fact, another possibility exists in which the poleward shift of the jet streams causes the increase in eddy length scale. This mechanism is supported by Barnes and Hartmann (2011), who demonstrated in a barotropic model that as the eddydriven jet is located at higher latitudes, the eddy length scale increases as suggested by linear Rossby theory.

\section{4) LINEAR REFRACTIVE INDEX}

The index of refraction, in particular the meridional wavenumber calculated from the linear QG model, was used to understand the equatorward displacement of the transient eddies, and the associated dynamical mechanisms, during El Niños (Seager et al. 2003; Harnik et al. 
(a) $150 \mathrm{mb} \cup[\mathrm{m} / \mathrm{s}]$

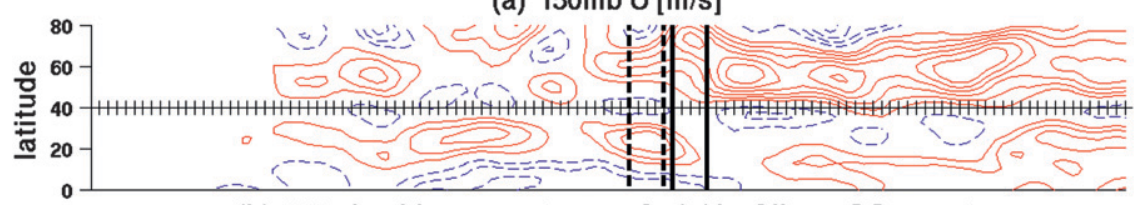

(b) $150 \mathrm{mb}$ eddy moment. conv. [m/s/day] linearQG wave6

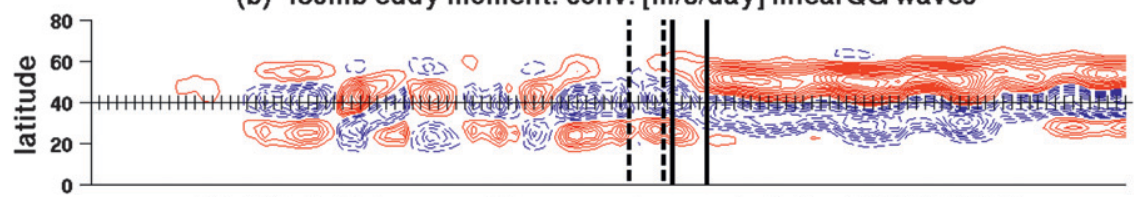

(c) $150 \mathrm{mb}$ high-pass eddy moment. conv. [m/s/day] CAM3-SOM

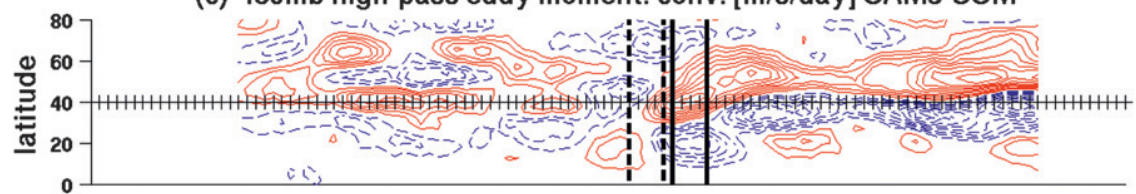

(d) $500 \mathrm{mb} \cup[\mathrm{m} / \mathrm{s}]$

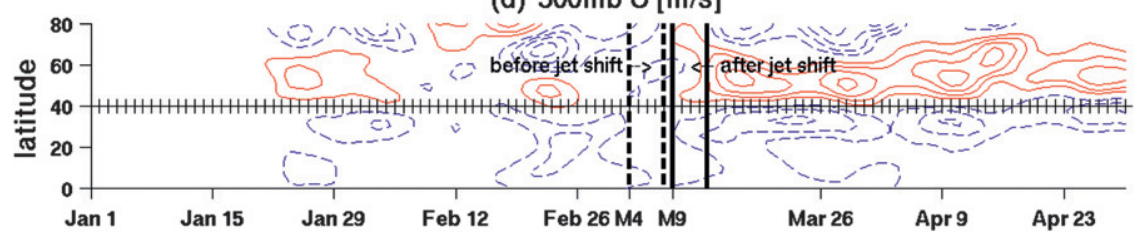

FIG. 9. The day-by-day zonal mean anomaly of (a) the zonal flow at $150 \mathrm{mb}$, (b) the $150-\mathrm{mb}$ eddy momentum flux convergence output from the linear QG model, (c) the 150-mb high-pass filtered transient eddy momentum flux convergence calculated from the CAM3-SOM runs, and (d) the zonal wind at $500 \mathrm{mb}$. A 5-day temporal running average has been applied. Red solid (blue dashed) contours indicate positive (negative) values. The contour intervals are $0.25 \mathrm{~m} \mathrm{~s}^{-1}$ for (a) and (d) and $0.025 \mathrm{~m} \mathrm{~s}^{-1}$ day $^{-1}$ for (b) and (c). Dashed (solid) vertical lines indicate the 5-day time interval before (after) 500-mb jet shift from 4 (9) March to 8 (13) March.

2010). They showed that during El Niños, as a consequence of the equatorward shift of the subtropical jets and resulting changes in meridional wavenumber, the transient eddies act to persistently maintain the mean flow anomalies via anomalous convergence (divergence) of momentum flux in the subtropical (midlatitude) region. Simpson et al. (2009) also successfully used the index of refraction to diagnose and interpret how changing eddy propagation and eddy momentum fluxes drive anomalous tropospheric circulation as a result of initial stratospheric heating perturbations applied in a simple GCM.

In this section, we use the linear QG model from Harnik and Lindzen (2001) to isolate the effect of linear wave refraction and to quantify the transient eddy feedback to the tropospheric zonal flow. For typical transient waves in the troposphere, a zonal wavenumber of 6 and a eddy phase speed of about $10 \mathrm{~m} \mathrm{~s}^{-1}$ is prescribed in the linear QG model. ${ }^{6}$ Here we assume

\footnotetext{
${ }^{6}$ We have used the same set of model parameters as in Seager et al. (2003) and Harnik et al. (2010).
}

constant $k$ and $C_{p}$ for both the $1 \mathrm{CO}_{2}$ and the $2 \mathrm{CO}_{2} \mathrm{ex}$ periments, which is different from sections 1 and 3 and assumes no changes in eddy properties. As will be shown in the following, changes in eddy propagation as a result of changes in the index of refraction (with constant $k$ and $C_{p}$ ) are able to capture the tropospheric jet shift. Daily zonal mean zonal wind and temperature fields from each day of the 120-day adjustment process averaged across the 100 ensemble runs are used as input for the linear QG model, and the corresponding daily steady-state eddy fluxes are calculated numerically.

Figure 9 shows the day-by-day evolution of the anomalies in 150-mb zonal mean zonal wind from the CAM3-SOM experiments, 150 -mb horizontal eddy momentum flux convergence (HEMFC) calculated from the linear QG model, for comparison, and the 150-mb highpass filtered HEMFC and 500-mb zonal mean zonal wind from the CAM3-SOM experiments. The values 150 and $500 \mathrm{mb}$ are chosen to represent the lower stratosphereupper troposphere and the midtroposphere, respectively, and similar results can be obtained for other vertical layers. A 5-day temporal running average has been applied to these variables and the results shown in Fig. 9 
(a) $U$ (before jet shift) \& EMFC linearQG

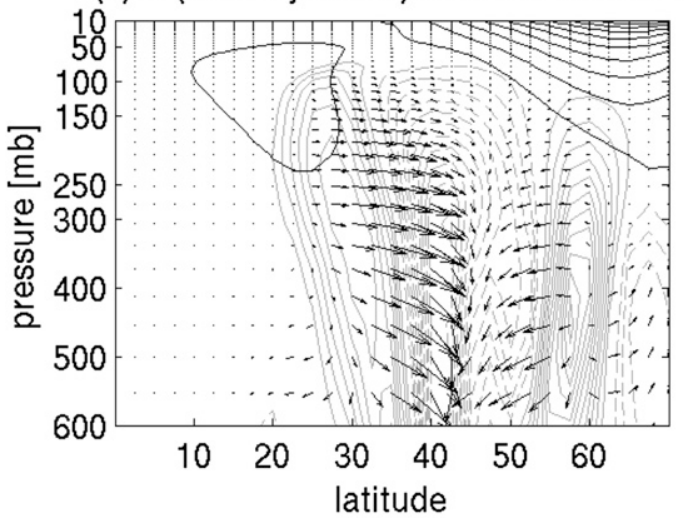

(c) $U$ (before jet shift) + EMFC linearQG

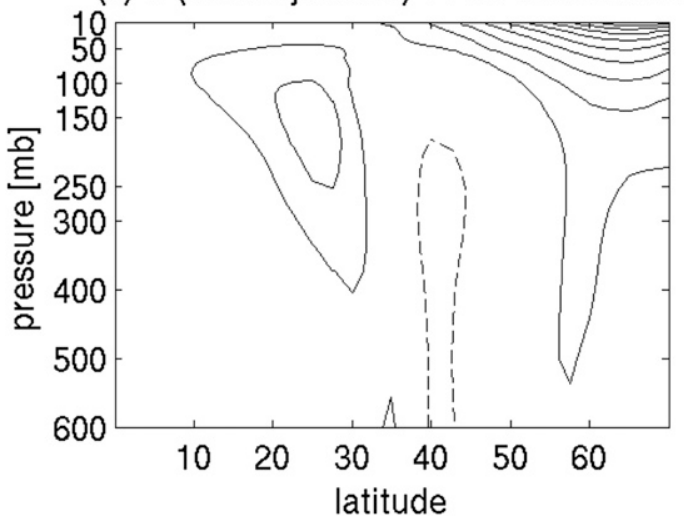

(b) $I^{2}$ (with $U$ before jet shift) linearQG

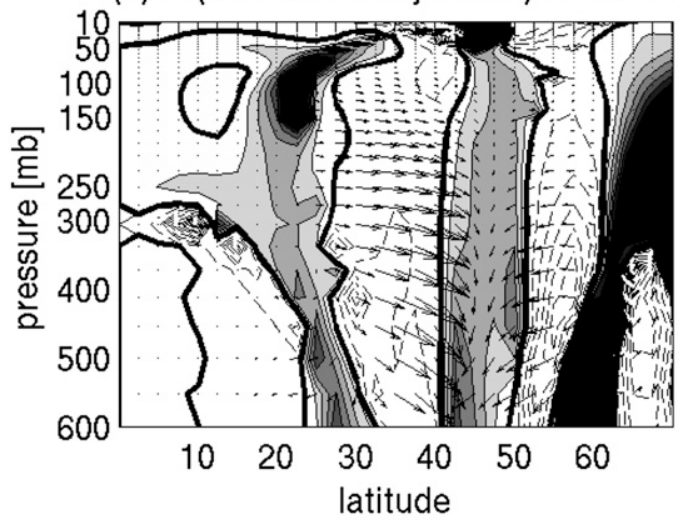

(d) $\cup$ (after jet shift)

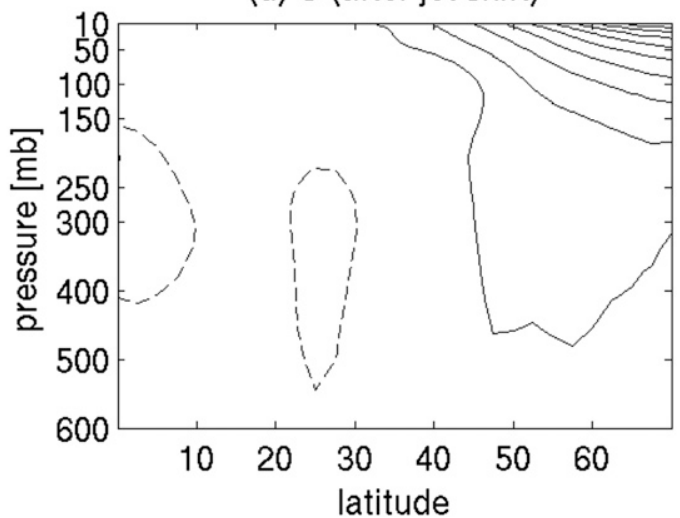

FIG. 10. (a) The zonal wind anomaly from CAM3-SOM experiments before the 500-mb jet shift (5-day average from 4 to $8 \mathrm{March}$ ) (black contours) and resulting transient eddy propagation (shown in EP flux vectors) and horizontal eddy momentum flux convergence (HEMFC) calculated from the linear QG model (gray contours). The contour intervals are $0.5 \mathrm{~m} \mathrm{~s}^{-1}$ for $u$ and $0.5 \mathrm{~m} \mathrm{~s}^{-1}$ day ${ }^{-1}$ for HEMFC. (b) The change in meridional wavenumber $\left(l^{2}\right)$ calculated from the linear QG model and corresponding EP flux anomalies. Positive changes in $l^{2}$ are highlighted in gray/black colors. (c) The "implied" zonal wind anomaly and is the sum of the zonal wind anomaly before the 500-mb jet shift and the increment induced by the HEMFC calculated from the linear QG model. (d) The zonal wind anomaly after the 500-mb jet shift (5-day average from 9 to $13 \mathrm{March}$ ) from CAM3-SOM experiments. The contour intervals are $0.5 \mathrm{~m} \mathrm{~s}^{-1}$.

are robust for other running averages. As shown in Figs. $9 \mathrm{a}, 9 \mathrm{c}$, and $9 \mathrm{~d}$, the intensified convergence of transient eddy momentum flux at $150 \mathrm{mb}$ occurs roughly on 5 March after the westerly anomalies in the extratropical lower stratosphere at $150 \mathrm{mb}$, followed by the $500-\mathrm{mb}$ tropospheric jet shift starting from 9 March. This suggests that the transient eddy momentum flux might play an important role in this downward migration process, enabling the zonal wind anomaly to propagate from the lower stratosphere to the troposphere. Furthermore, as shown in Figs. $9 \mathrm{~b}$ and $9 \mathrm{c}$, there is a qualitative agreement in the transient eddy momentum flux convergence response between the linear QG model and the CAM3SOM simulations, especially the well-organized and persistent dipole structure starting from mid-March. The response in the QG model suggests the important role of changes in the zonal mean basic state in causing the poleward shift of the tropospheric jet streams.

To further demonstrate how the zonal mean zonal wind response migrates downward from the lower stratosphere to the troposphere, we focus on two 5-day time intervals: 1 ) before the $500-\mathrm{mb}$ jet shift from 4 to 8 March (highlighted in dashed lines in Fig. 9) and 2) after the 500-mb jet shift from 9 to 13 March (highlighted in solid lines in Fig. 9). Figure 10a shows the zonal wind anomaly before the $500-\mathrm{mb}$ jet shift when the westerly intensification is primarily located in the stratosphere. As a result of this subpolar lower stratospheric westerly anomaly, the transient eddies in the troposphere respond by refracting equatorward in the linear QG model, as shown by the vectors in Fig. 10a, roughly from poleward of $50^{\circ} \mathrm{N}$ to equatorward of $50^{\circ} \mathrm{N}$. 
Figure 10b shows the change in meridional wavenumber $\left(l^{2}\right)$ calculated from the linear QG model and it shows that the change in eddy propagation follows the change in $l^{2}$, as expected, from negative to positive values. Further diagnosis shows that the change in $l^{2}$ in general follows that in $-(\partial / \partial \phi)[(1 / a \cos \phi)(\partial\langle u\rangle \cos \phi / \partial \phi)]$, which is the second term in the meridional PV gradient in Eq. (6) (not shown). In addition, the day-pressure plot of the dayby-day evolution of $-(\partial / \partial \phi)[(1 / a \cos \phi)(\partial\langle u\rangle \cos \phi / \partial \phi)]$ averaged over the midlatitudes also shows a feature of downward migration, taking place ahead of eddy responses (not shown). This anomalous propagation of transient eddies implies a westerly acceleration (deceleration) tendency poleward (equatorward) of $50^{\circ} \mathrm{N}$ in the troposphere right below the subpolar lower stratospheric wind anomaly, and this causes the poleward shift of the tropospheric jet streams. Figure 10c shows the "implied" zonal mean zonal wind anomaly by adding the contribution from the anomalous transient eddy momentum flux convergence due to changes in the index of refraction as calculated in the linear QG model (contours in Fig. 10a). As a comparison, Fig. 10d shows the actual zonal mean zonal wind anomaly averaged from 9 to 13 March from the CAM3-SOM simulations. There is a general agreement between Figs. 10c and 10d, in particular with regard to the poleward shift of the tropospheric jet streams. Therefore, as shown above, changes in the linear refractive index are able to explain the downward migration process.

The downward migration process from the lower stratosphere to the midtroposphere is accomplished step by step. In a schematic way, the zonal wind anomaly in the lower stratosphere (e.g., at $150 \mathrm{mb}$ ) changes the index of refraction and alters the eddy propagation at this level as well as at surrounding levels (e.g., at $250 \mathrm{mb}$ ), since transient eddies are vertically coupled. The anomalous eddy propagation at $250 \mathrm{mb}$ then further modifies the zonal mean zonal wind there. It is via this positive feedback between the zonal flow and the transient eddies that the zonal wind anomaly, step by step, propagates into the mid and lower troposphere. This step-by-step transient adjustment is similar to what was found in Simpson et al. (2009) where they successfully used the index of refraction to understand the tropospheric circulation response to stratospheric heating perturbations. They identified a positive feedback between tropospheric eddy fluxes and tropospheric circulation changes.

However, the linear refraction theory cannot capture the response of the subtropical jets in the upper troposphere. As shown in Figs. 4f and 4h, the CAM3-SOM simulations tend to weaken the subtropical jet from phase 2 to phase 3 . On the contrary, according to the results from the linear QG model, the subtropical jets strengthen (Figs. 10a,c). Hence, for the subtropical jet response, mechanisms other than linear refraction theory might be important and we leave this part for future studies.

Returning to the midlatitude jet, as shown in Figs. 9b and $9 \mathrm{c}$, after the tropospheric jet has shifted, transient eddies act to feed back positively onto the zonal wind by accelerating the zonal flow on the poleward flank between $40^{\circ}$ and $60^{\circ} \mathrm{N}$ while decelerating on the equatorward side. Therefore, it is the wave-mean flow interaction in the lower stratosphere that initiates the poleward movement of the tropospheric jet streams and the positive feedback between the zonal flow and the transient eddies acts to maintain the jet position change.

In the diagnosis of phase 2, it has been found that the stratospheric westerly acceleration is a consequence of increased equatorward refraction of stationary waves, which, however, cannot be interpreted from the theory of linear refraction. As discussed previously, the reason is probably related to the existence of the low model top that "artificially" alters the wave propagation. In contrast, in this section, we focus on the dynamics of transient wave 6 , which does not propagate into the stratosphere and the propagation and eddy fluxes are largely determined by the index of refraction, consistent with prior work (e.g., Seager et al. 2003; Simpson et al. 2009; Harnik et al. 2010).

\section{Discussions and conclusions}

The chain of causality underlying the atmospheric circulation responses to global warming is investigated. This was examined by analyzing the transient day-to-day and week-to-week forced changes of the average of 100 ensemble member model integrations after the $\mathrm{CO}_{2}$ concentration was instantaneously doubled. It is found that after a few months of integration, the circulation and thermal responses in the extratropical troposphere resemble the major features seen in the quasi-equilibrium simulations from the CMIP3/IPCC AR4 coupled models using the $\mathrm{A} 1 \mathrm{~B}$ emission scenario, which suggests the usefulness and relevance of examining the transient adjustment process.

Part I of the study mainly focused on the transient thermal response in the troposphere. It showed that the extensive warming in the upper and middle subtropical troposphere is caused adiabatically by the anomalous descending motion in this region driven by transient eddy momentum flux anomalies in the troposphere. Here, Part II explores the dynamical mechanisms underlying the sequential transient adjustment leading up 
to the establishment of the equilibrium circulation response in the extratropical troposphere. From the dayby-day evolution of the zonal mean zonal wind in the extratropics, three phases are defined. The initial response takes place in the stratosphere and involves a westerly flow anomaly in the low-latitude stratosphere, together with an easterly anomaly in the northern high latitudes, both driven radiatively by the $\mathrm{CO}_{2}$ increase and associated latitudinal gradients of the temperature response. The easterly anomaly in the northern highlatitude stratosphere switches to a westerly flow acceleration throughout the stratosphere in phase 2 driven by enhanced planetary-scale eddy horizontal momentum flux convergence. However, the index of refraction could not explain the eddy response in the stratosphere during phase 2 , and this may be related to the low model upper boundary and possible wave reflection. Phase 3 involves the "downward migration" of the westerly anomaly from the lower stratosphere into the troposphere, followed by the poleward shift of the tropospheric jet stream. Previous studies have proposed mechanisms that can cause a shift of the tropospheric jet and they are all examined here to see whether they can explain the tropospheric jet shift in our modeling experiments. Here we summarize the findings:

- We found no significant increase in eddy phase speed in either the transient adjustment or the equilibrium state, in contrast to previous studies by Lu et al. (2008) and Chen et al. (2008).

- The day-by-day evolution of the rise in tropopause height, averaged over the extratropics, appears to lead the tropospheric jet shift by a few days, but there is small correlation overall between the evolution of the two quantities. In addition, the dynamical mechanisms linking the tropopause height rise and the jet shift is not clear.

- The transient eddy length scale does increase but the lead-lag relation between the increase in eddy length scale and the poleward movement of the tropospheric jet streams is hard to identify. Thus the mechanism of Kidston et al. (2011) does not seem to work here.

- The poleward shift of the tropospheric jet streams can be captured by changes in the linear refractive index, due to westerly anomalies in the subpolar lower stratosphere, and the resulting changes in transient eddy propagation in the troposphere.

There are a few caveats in this study and future work is needed to achieve a better and more thorough understanding of the dynamics. First is the dependence of the transient response on the initial conditions. The radiative response strongly depends on the latitudinal distribution of the basic state temperature which controls the temperature anomaly following the $\mathrm{CO}_{2}$ doubling. Hence experiments starting from 1 January and others starting from 1 July are expected to behave differently. This suggests the necessity of another set of modeling experiments with an initial condition of 1 July. Second, although the initial radiative response in the $\mathrm{NH}$ wintertime is an equatorward shift of the polar jets with an easterly (westerly) anomaly at high (low) latitudes in the stratosphere, this feature is later strongly modified by planetary wave-mean flow interaction in the stratosphere. The planetary-scale waves are refracted more equatorward, leading to an acceleration of the westerly anomaly in the stratosphere. However, this response is not well understood and could possibly be caused by the existence of the low model lid and resulting downward wave reflection. Although this consequence of a low model upper boundary might be universal among other CMIP3/IPCC AR4 coupled climate models, it leads to another question of what the stratospheric and tropospheric circulation responses would be in a stratosphere-resolving model. For example, Scaife et al. (2012) demonstrated distinct circulation responses to climate change for standard (CMIP3/IPCC AR4) and stratosphere-resolving climate models [models for the Chemistry Climate Model Validation (CCMVal) project]. It should be noted that the difference in basic state between the two sets of models probably is not excluded as a cause of differences in the responses (Sigmond and Scinocca 2010).

Finally, in our model simulations, the stratospheric circulation responses in the two hemispheres are different. For example, the stratospheric polar jet strengthens in northern winter whereas that in southern winter shifts equatorward associated with an easterly (westerly) anomaly at high (low) latitudes (as shown in Figs. 3c and $3 \mathrm{~d}$ in Part I). This stratospheric zonal wind response is consistent in both the transient and equilibrium state in our model simulations. It is possible that the differences in both the radiative and dynamical adjustment for the two hemispheres cause the different circulation anomalies.

While the current work represents an advance in our understanding of the poleward shift of the jet stream and storm tracks in response to global warming, clearly more work is needed, especially with models with a wellresolved stratosphere, to fully understand this aspect of climate change.

Acknowledgments. The authors are grateful to three anonymous reviewers for their helpful comments. The authors would like to especially thank Lorenzo Polvani, Mark Cane, and Adam Sobel, and the Global Decadal Hydroclimate $(\mathrm{GloDecH})$ group at Lamont-Doherty 
Earth Observatory and Columbia University for their helpful comments and advice. We also appreciate discussions with Geoffrey K. Vallis, Nili Harnik, Joe Kidston, and Olivier Pauluis. We are grateful for support from the NASA Earth and Space Science Fellowship ProgramGrant NNX08AU80H (YW), the Department of EnergyAward DE-SC0005107 (YW and RS), the National Oceanic and Atmospheric Administration-Awards NA08OAR4320912 and NA10OAR4320137 (RS, MT, and NN), and the National Science Foundation-Award ATM-0804107 (RS, MT, and NN).

\section{REFERENCES}

Baldwin, M. P., and T. J. Dunkerton, 2001: Stratospheric harbingers of anomalous weather regimes. Science, 294, 581-584.

Barnes, E. A., and D. L. Hartmann, 2011: Rossby wave scales, propagation, and the variability of eddy-driven jets. J. Atmos. Sci., 68, 2893-2908.

Boville, B. A., 1984: The influence of the polar night jet on the tropospheric circulation in a GCM. J. Atmos. Sci., 41, 11321142.

— circulation model. J. Atmos. Sci., 45, 2592-2606.

Butler, A. H., D. W. J. Thompson, and R. Heikes, 2010: The steadystate atmospheric circulation response to climate change-like thermal forcings in a simple general circulation model. J. Climate, 23, 3474-3496.

Charney, J. G., and P. G. Drazin, 1961: Propagation of planetaryscale disturbances from the lower into the upper atmosphere. J. Geophys. Res., 66 (1), 83-109.

Chen, G., and I. M. Held, 2007: Phase speed spectra and the recent poleward shift of Southern Hemisphere surface westerlies. Geophys. Res. Lett., 34, L21805, doi:10.1029/2007GL031200.

— J. Lu, and D. M. W. Frierson, 2008: Phase speed spectra and the latitude of surface westerlies: Interannual variability and global warming trend. J. Climate, 21, 5942-5959.

Dee, D. P., and Coauthors, 2011: The ERA-Interim reanalysis: Configuration and performance of the data assimilation system. Quart. J. Roy. Meteor. Soc., 137, 533-597.

Edmon, H. J., B. J. Hoskins, and M. E. McIntyre, 1980: EliassenPalm cross sections for the troposphere. J. Atmos. Sci., 37, 2600-2616.

Harnik, N., and R. S. Lindzen, 2001: The effect of reflecting surfaces on the vertical structure and variability of stratospheric planetary waves. J. Atmos. Sci., 58, 2872-2894.

_, R. Seager, N. Naik, M. Cane, and M. Ting, 2010: The role of linear wave refraction in the transient eddy-mean flow response to tropical Pacific SST anomalies. Quart. J. Roy. Meteor. Soc., 136, 2132-2146, doi:10.1002/qj.688.

Kidston, J., S. M. Dean, J. A. Renwick, and G. K. Vallis, 2010: A robust increase in eddy length scale in the simulation of future climates. Geophys. Res. Lett., 37, L03806, doi:10.1029/ 2009GL041615.

— , G. K. Vallis, S. M. Dean, and J. A. Renwick, 2011: Can the increase in the eddy length scale under global warming cause the poleward shift of the jet streams? J. Climate, 24, 3764-3780.

Kushner, P. J., I. M. Held, and T. L. Delworth, 2001: Southern Hemisphere atmospheric circulation response to global warming. J. Climate, 14, 2238-2249.
Lorenz, D. J., and E. T. DeWeaver, 2007: Tropopause height and zonal wind response to global warming in the IPCC scenario integrations. J. Geophys. Res., 112, D10119, doi:10.1029/ 2006JD008087.

Lu, J., G. A. Vecchi, and T. Reichler, 2007: Expansion of the Hadley cell under global warming. Geophys. Res. Lett., 34, L06805, doi:10.1029/2006GL028443.

— G. Chen, and D. M. W. Frierson, 2008: Response of the zonal mean atmospheric circulation to El Niño versus global warming. J. Climate, 21, 5835-5851.

— C. Deser, and T. Reichler, 2009: Cause of the widening of the tropical belt since 1958. Geophys. Res. Lett., 36, L03803, doi:10.1029/2008GL036076.

Matsuno, T., 1970: Vertical propagation of stationary planetary waves in the winter Northern Hemisphere. J. Atmos. Sci., 27, 871-883.

O'Gorman, P. A., 2010: Understanding the varied response of the extratropical storm tracks to climate change. Proc. Natl. Acad. Sci. USA, 107, 19 176-19 180.

Perlwitz, J., and N. Harnik, 2003: Observational evidence of a stratospheric influence on the troposphere by planetary wave reflection. J. Climate, 16, 3011-3026.

Randel, W. J., and I. Held, 1991: Phase speed spectra of transient eddy fluxes and critical layer absorption. J. Atmos. Sci., 48 , 688-697.

Reichler, T., M. Dameris, and R. Sausen, 2003: Determining the tropopause height from gridded data. Geophys. Res. Lett., 30, 2042, doi:10.1029/2003GL018240.

Riviére, G., 2011: A dynamical interpretation of the poleward shift of the jet streams in global warming scenarios. J. Atmos. Sci., 68, 1253-1272.

Santer, B. D., and Coauthors, 2003: Contributions of anthropogenic and natural forcing to recent tropopause height changes. Science, 301, 479-483.

Sassi, F., R. R. Garcia, D. Marsh, and K. W. Hoppel, 2010: The role of the middle atmosphere in simulations of the troposphere during Northern Hemisphere winter: Differences between high- and low-top models. J. Atmos. Sci., 67, 3048-3064.

Scaife, A. A., and Coauthors, 2012: Climate change projections and stratosphere-troposphere interaction. Climate Dyn., 38, 20892097, doi:10.1007/s00382-011-1080-7.

Seager, R., N. Harnik, Y. Kushnir, W. Robinson, and J. Miller, 2003: Mechanisms of hemispherically symmetric climate variability. J. Climate, 16, 2960-2978.

Seidel, D. J., and W. J. Randel, 2007: Recent widening of the tropical belt: Evidence from tropopause observations. J. Geophys. Res., 112, D20113, doi:10.1029/2007JD008861.

Seviour, W. J. M., N. Butchart, and S. C. Hardiman, 2011: The Brewer-Dobson circulation inferred from ERA-Interim. Quart. J. Roy. Meteor. Soc., 138, 878-888, doi:10.1002/qj.966.

Shaw, T. A., and J. Perlwitz, 2010: The impact of stratospheric model configuration on planetary-scale waves in Northern Hemisphere winter. J. Climate, 23, 3369-3389.

$\ldots,-$, and N. Harnik, 2010: Downward wave coupling between the stratosphere and troposphere: The importance of meridional wave guiding and comparison with zonal-mean coupling. J. Climate, 23, 6365-6381.

Sigmond, M., and J. F. Scinocca, 2010: The influence of the basic state on the Northern Hemisphere circulation response to climate change. J. Climate, 23, 1434-1446.

_, P. C. Siegmund, E. Manzini, and H. Kelder, 2004: A simulation of the separate climate effects of middle-atmospheric and tropospheric $\mathrm{CO}_{2}$ doubling. J. Climate, 17, 2352-2367. 
_- J. F. Scinocca, and P. J. Kushner, 2008: Impact of the stratosphere on tropospheric climate change. Geophys. Res. Lett., 35, L12706, doi:10.1029/2008GL033573.

Simpson, I. R., M. Blackburn, and J. D. Haigh, 2009: The role of eddies in driving the tropospheric response to stratospheric heating perturbations. J. Atmos. Sci., 66, 13471365.

Wu, Y., M. Ting, R. Seager, H.-P. Huang, and M. A. Cane, 2011: Changes in storm tracks and energy transports in a warmer climate simulated by the GFDL CM2.1 model. Climate Dyn., 37, 53-72, doi:10.1007/s00382-010-0776-4.

R. Seager, M. Ting, N. H. Naik, and T. A. Shaw, 2012: Atmospheric circulation response to an instantaneous doubling of carbon dioxide. Part I: Model experiments and transient thermal response in the troposphere. J. Climate, 25, 2862-2879.

Yin, J. H., 2005: A consistent poleward shift of the storm tracks in simulations of 21 st century climate. Geophys. Res. Lett., 32, L18701, doi:10.1029/2005GL023684. 